\title{
European Stock Market Integration: Does EMU Matter?
}

\author{
Jian Yang, Insik Min and Qi Li*
}

\section{INTRODUCTION}

Numerous recent studies (e.g., Eun and Shim, 1989; Koch and Koch, 1991; Brocato, 1994; Leachman and Francis, 1995; Francis and Leachman, 1998; and Bessler and Yang, 2003) have explored the long-term cointegration relations and/or shortterm dynamic interactions among major international stock markets, which also involve some major European stock markets. Parallel to these studies on major international stock markets, there is also a growing literature with a focus on stock markets within Europe. Taylor and Tonks (1989) and Corhay, Rad and Urbain (1993) found much evidence for cointegration among several major European stock markets in the late 1970s and 1980s. Dickinson (2000) argued that a cointegrating relationship among the major European stock markets exists after the

\footnotetext{
* The authors are respectively from the Department of Accounting, Finance and Information Systems, Prairie View A\&M University; the Department of Economics, Kyung Hee University; and the Department of Economics, Texas A\&M University and Department of Economics, Tsinghua University. They would like to thank an anonymous referee for helpful comments that significantly improved the paper. Li's research is supported by the Bush Program in the Economics of Public Policy, and the Private Enterprise Research Center, Texas A\&M University. An earlier version of this paper was awarded the 2003 Academy of International Business (US Southwest) McGraw-Hill/Irwin Distinguished Paper Award. (Paper received April 2002, revised and accepted September 2002)
}

Address for correspondence: Jian Yang, Department of Accounting, Finance and Information Systems, Prairie View A\&M University, Prairie View, TX 77446, USA. e-mail: jian_yang@pvamu.edu 
1987 stock crash and it may be partly driven by the long-run relationships of macroeconomic fundamentals among these countries. Dickinson (2000) also observed that short-run international linkages among major European markets which do not appear in their long-run relationship increased greatly during that period. By contrast, Chan, Gup and Pan (1997) found little evidence for cointegration among several major European stock markets and among most European Economic Community member countries, particularly during the period after the 1987 crash. Gerrits and Yuce (1999) documented that the long-run relationship among major European markets has weakened during the period 1990-1994. Pynnonen and Knif (1998) and Knif and Pynnonen (1999) extended consideration to small European (developed) markets. Pynnonen and Knif (1998) reported little interaction between two Scandinavian stock markets, while Knif and Pynnonen (1999) found some positive evidence on the interdependence among small European markets. Thus, the existing findings are inconclusive and further analysis is warranted.

In this paper we investigate market integration among European stock markets. Our study extends the existing literature in several ways. First, this study examines the possible impact of the Economic and Monetary Union (EMU) on stock market linkages. The introduction of a new common currency (i.e., the Euro) and a single monetary policy among eleven European Union member countries under the EMU mark the most dramatic development in international finance since the collapse of the Bretton Woods system. In a broad sense, the EMU represents the highest level of regional economic integration that has ever been reached. However, with the possible exception of Leachman and Francis (1995), the issue of how macroeconomic policy coordination in general, and regional economic integration in particular, may affect stock market integration has received little attention in the literature.

Second, this study allows for inference on international market integration from three different perspectives: contemporaneous, the short-run and the long-run. Except Taylor and Tonks (1989), Brocato (1994) and Bessler and Yang (2003), the contemporaneous structure of international market integration based on return innovations has not been much analyzed in 
previous studies employing time series analysis, though Mahmoud and Malek (1993) reported that stock market responses within Europe may be predominantly contemporaneous. The existence of strong contemporaneous correlations further motivates our modeling the short-run dynamic linkage with the generalized impulse response analysis/forecast error variance decomposition originally developed by Koop, Pesaran and Potter (1996) and Pesaran and Shin (1998). This approach is invariant to the ordering of the variables when conducting vector autoregression (VAR) innovation accounting analysis, while the widely used Choleski factorization is known to be sensitive to the ordering of the variables. Recently, generalized VAR analysis has been argued to give a more realistic description of stock market linkages (Dekker, Sen and Young, 2001; and Yang, Kolari and Min, 2003). In addition, a tool developed by Pesaran and Shin (1996) is employed to examine the impact of the EMU on the long-run structure of integration among European stock markets.

Finally, this study explores the possible different market behaviors between large and small stock markets. Small (developed) stock markets generally have not received much attention in the literature. A number of the small stock markets included in this study have not been previously examined in conjunction with each other or with other large markets. With most similar macroeconomic environments as applied to the EMU members, the role of the market size per se in shaping the international market linkage may be examined more thoroughly. The main finding of the paper is that most EMU stock markets have become more interdependent after the establishment of EMU. The rest of the paper is organized as follows. Section 2 discusses the proposed methodology. Section 3 describes the data. Section 4 presents the empirical results, and Section 5 concludes.

\section{EMPIRICAL METHODOLOGY}

This section provides a brief overview of the empirical methodology used in this study to facilitate analysis of the long-run, short-run and instantaneous patterns of European stock market integration. Let $X_{t}$ denote a vector which includes 
$m$ nonstationary variables ( $m=12$ in this study). Assuming existence of cointegration, the data generating process of $X_{t}$ can be appropriately modeled in an error correction model (ECM) with $p-1$ lags (which is derived from a VAR in levels with $p$ lags):

$$
\Delta X_{t}=\Pi X_{t-1}+\sum_{i=1}^{p-1} \Gamma_{i} \Delta X_{t-i}+\mu+\varepsilon_{t} \quad(t=1, \ldots, T)
$$

where $\Pi=\alpha \beta^{\prime}, \alpha$ and $\beta$ are $m \times r$ matrices of full rank $r$ ( $r$ is the number of cointegrating vectors, $\Gamma_{i}$ is of dimension $m \times m$ and $\varepsilon_{t} \sim \ddot{i i d}\left(0, \sum\right)$.

The impact of the EMU on the long-run structure of European stock market integration can be examined by comparing cointegration relations among the eleven European stock markets and the US in period 1 and period 2. A priori expectation is that EMU stock markets are likely to be more integrated (particularly among themselves but also possibly with the rest of the world) in period 2, which may be captured by the increase in the number of cointegrating vectors. As mentioned previously, the introduction of the EMU starts an era when both monetary policies and (to some extent) fiscal polices in EMU member countries are more coordinated, which may result in more similar domestic economic conditions in these countries. As pointed out in Ripley (1973, p.356), stock market prices to a much greater extent reflect domestic economic conditions in each country. Hence, stock markets in EMU member countries should be more integrated as a result of more similar domestic economic conditions across countries after establishment of the EMU. The number of cointegrating vectors is determined by the rank of $\Pi=\alpha \beta^{\prime}$. The trace test statistics (Johansen and Juselius, 1990; and Johansen, 1991) can be calculated to test the number of cointegrating vectors.

Once the system is shocked (Pesaran and Shin, 1996, p.118), it is important that analysis of cointegration relationships is accompanied by some estimates of the speed with which the markets under consideration return to their equilibrium states. Such an analysis would be particularly valuable in cases where there are two or more cointegrating relations characterizing equilibrium. In this study, the persistence profile technique developed in Pesaran and Shin (1996) is employed to model 
the time profile of the effect of a system-wide shock on the cointegrating relations. This can produce more fruitful information on the nature of the long-run structure of market integration. Even if the impact of the EMU is not reflected in a change in the number of cointegrating vectors, a faster speed of adjustment to equilibrium is still an indication that the EMU cause European stock markets to be more integrated in the long run.

The short-run structure of stock market integration involves two parts, $\alpha$ and $\Gamma_{i}$. The parameter $\alpha$ defines the error correction adjustment through which the system is pulled back to its long-run equilibrium, while the parameters $\left(\Gamma_{1}, \ldots, \Gamma_{p-1}\right)$ define the short-run adjustment to changes in the variables. However, it is well recognized that like in a standard VAR, the individual coefficients of the ECM are hard to interpret (Sims, 1980; and Lutkepohl and Reimers, 1992). Under such cases, innovation accounting may be the best description of the shortrun dynamic structure. It was common in earlier VAR-type analyses to rely on a Choleski factorization. Unfortunately, the innovation accounting result based on the Choleski factorization is sensitive to the ordering of variables when the residual covariance matrix is non-diagonal. In this study, we apply generalized impulse response analysis and generalized forecast error variance decomposition developed in Koop, Pesaran and Lee (1996) and Pesaran and Shin (1998) to deal with this problem. Unlike the orthogonalized impulse response function and forecast error variance decomposition, the generalized approach is invariant to the ordering of the variables in the VAR model.

From model (1), we can write $\Delta X_{t}$ as an infinite moving average process:

$$
\Delta X_{t}=\sum_{i=0}^{\infty} C_{i} \varepsilon_{t-i}, t=1,2, \ldots, T .
$$

The (scaled) generalized impulse response function which measures the effect on $\Delta X_{t+n}$ of the shock to the $j$ th equation in equation (1) is given by Pesaran and Shin (1998) to be:

$$
\psi_{j}(n)=\sigma_{j j}^{-1 / 2} C_{n} \sum e_{j}, n=0,1,2, \ldots,
$$


where $\sigma_{j j}$ is $j j$ th element of the variance-covariance matrix $\sum$ and $e_{j}$ is a $m \times 1$ vector with unity at the $j$ th row and zeros elsewhere. The generalized impulse response function can provide insight into how significantly innovations in a particular market in the system may affect other markets through dynamic interactions among markets. The generalized forecast error variance decomposition is given by:

$$
\theta_{i j}(n)=\frac{\sigma_{i i}^{-1} \sum_{l=0}^{n}\left(e_{j}^{\prime} C_{l} \sum e_{j}\right)^{2}}{\sum_{l=0}^{n}\left(e_{i}^{\prime} C_{l} \sum C_{l}^{\prime} e_{i}\right)}, i, j=1,2, \ldots, m .
$$

The generalized forecast error variance decomposition reveal to what extent price variation of a certain market can be explained by innovations from other markets in the system. It can be used to measure the relative importance of other markets in driving market returns in a particular market.

Finally, a possible change in the contemporaneous structure of market integration may be explored by examining equality of correlation coefficients of innovations in contemporaneous time across markets, based on the variance-covariance matrix of innovations (i.e., residuals from the ECM). Specially, following Taylor and Tonks (1989) and Brocato (1994), the test statistic can be constructed as follows. If $\hat{\rho}$ is the sample correlation coefficient between two markets (and the sample size is greater than fifty), a statistic $\xi$, which is approximately normally distributed can be constructed as follows (Kendall and Stuart, 1967):

$$
\xi=\frac{1}{2} \cdot \ln \left(\frac{1+\hat{\rho}}{1-\hat{\rho}}\right) \sim N\left[\frac{1}{2} \cdot \ln \left(\frac{1+\rho}{1-\rho}\right), \frac{1}{T-3}\right]
$$

where $\rho$ is the population correlation coefficient and $T$ is the sample size. The test statistic for equality of the correlation coefficients between period 1 and period 2 can be generally constructed as $\zeta=\frac{\xi_{1}-\xi_{2}}{\sqrt{\operatorname{var}\left(\xi_{1}\right)+\operatorname{var}\left(\xi_{2}\right)}}$, where $\xi_{j}$ is the test statistic in (5) for period $j(j=1,2)$.

Hence, the test statistic for $H_{0}: \rho_{1}=\rho_{2}$ is given by: 


$$
\zeta=\frac{\frac{1}{2}\left\{\ln \left[\left(1+\hat{\rho}_{1}\right) /\left(1-\hat{\rho}_{1}\right)\right]-\ln \left[\left(1+\hat{\rho}_{2}\right) /\left(1-\hat{\rho}_{2}\right)\right]\right\}}{\sqrt{\left\{1 /\left(T_{1}-3\right)+1 /\left(T_{2}-3\right)\right\}}} \sim N(0,1) .
$$

If the test statistic rejects the null hypothesis, it is concluded that there is a significant difference in correlation coefficients between the two periods. A significant increase in the correlation coefficient may imply that the two stock markets have become more integrated instantaneously (Taylor and Tonks, 1989, p. 333).

\section{DATA}

The data used in this study consist of the daily stock index closing price of ten EMU countries, ${ }^{1}$ the UK and US. Specifically, they include Germany (GER) DAX, France (FRA) CAC 40, Italy (ITA) MIB30, Netherlands (NET) AEX, Austria (AUS) ATX, Belgium (BEL) BEL 20, Finland (FIN) FOX, Ireland (IRE) SE General, Portugal (POR) PSI 20, Spain (SPA) IBEX 35, the UK (UK) FTSE 100 and the US (US) S\&P 500. These stock market indexes are comprehensive and (with the exception of Ireland) there exists stock index futures trading directly based on all these indices. Inclusion of the UK and US is important for two reasons. First, it facilitates a deeper understanding of the EMU impact by examining how market integration between EMU markets and the rest of world changed after the EMU was established. Second, it is necessary to include these markets as they may be expected to have certain strong linkage with the EMU markets. As illustrated in Janakiramanan and Lamba (1998) and Dekker, Sen and Young (2001), market linkage patterns among the EMU markets (which is of primary interest in the paper) may be distorted by failure to allow for the possible indirect influence of the US and UK.

As suggested by the literature (e.g., Taylor and Tonks, 1989; and Corhay, Rad and Urbain, 1993) and can be seen from Table 1, four major EMU markets (GER, FRA, ITA and NET), as well as the UK and the US, may be categorized as large stock markets. The other six EMU countries (AUS, BEL, FIN, IRE, POR and SPA) may be classified as small stock markets. The sample period is from January 1, 1996 to June 1, 
Table 1

The Stock Market Size During 1996-1999

\begin{tabular}{lrrrr}
\hline & \multicolumn{4}{c}{ Market Capitalization $($ End of the year, US\$ millions) } \\
\cline { 2 - 5 } Market & \multicolumn{1}{c}{1996} & \multicolumn{1}{c}{1997} & \multicolumn{1}{c}{1998} & \multicolumn{1}{c}{1999} \\
\hline US & $8,484,433$ & $11,308,779$ & $13,451,352$ & $16,635,114$ \\
UK & $1,740,246$ & $1,996,225$ & $2,374,273$ & $2,933,280$ \\
Germany & 670,997 & 825,233 & $1,093,962$ & $1,432,190$ \\
France & 591,123 & 674,368 & 991,484 & $1,475,457$ \\
Italy & 258,160 & 344,655 & 569,731 & 728,273 \\
Netherlands & 378,721 & 468,736 & 603,182 & 695,209 \\
Spain & 242,779 & 290,383 & 402,180 & 431,668 \\
Finland & 63,078 & 73,322 & 154,518 & 349,409 \\
Belgium & 119,831 & 136,965 & 245,657 & 184,942 \\
Portugal & 24,660 & 38,954 & 62,954 & 66,488 \\
Ireland & 12,242 & 24,134 & 29,956 & 42,458 \\
Austria & 33,953 & 35,724 & 34,106 & 33,025 \\
Luxembourg & 32,692 & 33,892 & 35,403 & 35,940 \\
\hline
\end{tabular}

Sources:

Emerging Stock Markets Factbook 2000 (p.17), Standard \& Poor's, New York.

2001, totaling, 1,415 daily observations for each series. The sample period can be further divided into two subperiods: the period before the EMU (1996.1.1-1998.12.31: Period 1) and the period after the EMU (1999.1.1-2001.6.1: Period 2). ${ }^{2}$ The EMU was established on January 1, 1999. The unprecedented policy changes under the EMU distinguish it from its predecessor European Monetary System (EMS) in three main aspects. First, a common monetary policy is carried out for all EMU member countries. The European Central Bank replaced the national central banks of EMU members and assumed responsibility for the conduct of a unified monetary policy on January 1, 1999. Second, effective on January 1, 1999, the Euro replaced the national currencies of EMU member countries, which eliminated the exchange rate volatility within the EMU member countries. Third, domestic fiscal and related policies of the member countries are coordinated. After the establishment of the EMU, member government budget deficits and borrowings should not exceed $3 \%$ and $60 \%$ of national incomes, respectively. As the ten EMU countries share the same common currency in period 2 and also had quasi-fixed exchange rates in 
Table 2

ADF Unit Root Test Results

\begin{tabular}{|c|c|c|c|c|}
\hline \multirow[b]{2}{*}{ Market } & \multicolumn{2}{|c|}{ Period 1} & \multicolumn{2}{|c|}{ Period 2} \\
\hline & Without Trend & With Trend & Without Trend & With Trend \\
\hline Germany & -1.70 & -1.63 & -1.35 & -1.18 \\
\hline France & -0.74 & -2.28 & -1.46 & -0.83 \\
\hline Italy & -0.33 & -2.14 & -1.26 & -1.14 \\
\hline Netherlands & -0.87 & -1.92 & -1.54 & -1.44 \\
\hline Austria & -1.60 & -0.99 & -2.64 & -2.91 \\
\hline Belgium & -0.41 & -2.74 & -2.82 & -3.09 \\
\hline Finland & -1.11 & -1.90 & -1.38 & -0.82 \\
\hline Ireland & -1.63 & -1.11 & -1.16 & -2.40 \\
\hline Portugal & -1.07 & -1.28 & -0.92 & -0.91 \\
\hline Spain & -0.74 & -1.84 & -1.88 & -1.91 \\
\hline UK & -0.77 & -2.38 & -2.68 & -2.94 \\
\hline US & -0.49 & -2.89 & -2.17 & -2.15 \\
\hline
\end{tabular}

Notes:

The critical values (with trend): -3.97 at the $1 \%$ level and -3.41 at the $5 \%$ level; the critical values (without trend): -3.44 at the $1 \%$ level and -2.86 at the $5 \%$ level.

period 1, the following analysis is based on data in local currency terms. ${ }^{3}$ The price series used in the study have been transformed by taking natural logarithms of the raw data. All the data are obtained from Datastream.

Two standard unit root test procedures are applied. One is the augmented Dickey-Fuller (ADF) test (Dickey and Fuller, 1981) and the other is the Phillips-Perron (PP) test (Phillips and Perron, 1988). Both tests are considered with and without trend. Table 2 reports ADF test results for $I(1)$ versus $I(0)$. The null hypothesis in each test is that each of the price series contains a unit root (i.e., I(1)) and it should be rejected if the test statistics are less than the critical value. The selection of optimal lags is determined by minimizing AIC. For every price index series, the null hypothesis of a unit root is not rejected at the $5 \%$ significance level in both periods. To verify that the order of integration is 1 , we also tested for the presence of a unit root in the first difference of stock price indexes and found no unit roots in first differenced series. The PP test results (not reported here) are qualitatively the same as ADF test results. 


\section{EMPIRICAL RESULTS}

The twelve stock market index prices are modeled as in equation (1). The choice of optimal lags for equation (1) is given by considerations of minimizing AIC and presence of no autocorrelation in the VAR residuals. Six lags for the levels of variable are chosen for period 1 and two lags are chosen for period 2 . The fewer number of lags in period 2 hints that the information transmission among the eleven European markets and the US is more efficient after the establishment of the EMU, which is more formally shown below. The trace test results for cointegration are reported in Table 3 .

Both with and without a linear trend, trace test results show that two cointegrating vectors exist at the $5 \%$ significance level in both period 1 and period 2. Because the number of cointegrating vectors is the same in both periods, this result does not indicate an increasing degree of integration in period 2. We further examine the persistence profile of the cointegrating vectors (Figure 1), which follows Pesaran and Shin (1996). Both cointegrating vectors in both periods are restored to the equilibrium after a system-wide shock. Further, both cointegrating vectors converge to the equilibrium much more quickly in period 2 than in period 1. Specifically, as plotted in Figure. 1, the two cointegrating vectors (CV) take 17 days and 14 days, respectively, to reach the level of 0.01 in period 2 (a practical approximation for zero, the equilibrium state), while they take 31 days and 37 days, respectively, to reach the same level in period 1. Thus, this finding suggests that European stock markets as a whole are more integrated in the long run in period 2 as deviations from equilibrium are shorter lived.

Based on the estimated ECMs in the two periods, we conduct the generalized forecast error variance decompositions, which are given in Table 4 and Table 5 for period 1 and period 2, respectively. To conserve space, the tables only provide 20 day ahead forecast error variance decompositions of stock market returns, which are representative of the results at other days (available upon request from the authors). Tables 4 and 5 indicate that there exist large differences between the two periods regarding stock market integration among the ten EMU stock markets. Some notable findings are as follows. 
Table 3

Trace Test Results

\begin{tabular}{|c|c|c|c|c|}
\hline \multirow[b]{2}{*}{$\begin{array}{l}\text { Number of } \\
\text { Cointegrating Vectors }\end{array}$} & \multicolumn{2}{|c|}{ Without Linear Trend } & \multicolumn{2}{|c|}{ With Linear Trend } \\
\hline & Test Statistic & $\begin{array}{l}\text { Critical Value } \\
(5 \%)\end{array}$ & Test Statistic & $\begin{array}{c}\text { Critical Value } \\
(5 \%)\end{array}$ \\
\hline \multicolumn{5}{|l|}{ Panel A: Period 1} \\
\hline$r=0$ & 369.08 & 338.09 & 348.41 & 323.93 \\
\hline$r=1$ & 297.26 & 289.70 & 278.58 & 276.36 \\
\hline$r=2$ & 234.97 & 244.56 & 218.58 & 232.60 \\
\hline$r=3$ & 180.91 & 203.34 & 164.63 & 192.30 \\
\hline$r=4$ & 140.98 & 165.73 & 126.96 & 155.74 \\
\hline$r=5$ & 106.36 & 132.00 & 92.51 & 123.03 \\
\hline$r=6$ & 78.30 & 101.83 & 66.16 & 93.91 \\
\hline$r=7$ & 53.53 & 75.73 & 41.51 & 68.86 \\
\hline$r=8$ & 33.62 & 53.42 & 23.59 & 47.20 \\
\hline$r=9$ & 20.30 & 34.79 & 11.81 & 29.37 \\
\hline$r=10$ & 10.27 & 19.99 & 4.97 & 15.34 \\
\hline$r=11$ & 3.95 & 9.13 & 1.01 & 3.84 \\
\hline \multicolumn{5}{|l|}{ Panel B: Period 2} \\
\hline$r=0$ & 367.30 & 338.09 & 358.33 & 323.93 \\
\hline$r=1$ & 292.91 & 289.70 & 283.95 & 276.36 \\
\hline$r=2$ & 231.70 & 244.56 & 223.21 & 232.60 \\
\hline$r=3$ & 174.58 & 203.34 & 166.20 & 192.30 \\
\hline$r=4$ & 137.10 & 165.73 & 129.08 & 155.74 \\
\hline$r=5$ & 101.73 & 132.00 & 93.77 & 123.03 \\
\hline$r=6$ & 77.12 & 101.83 & 69.21 & 93.91 \\
\hline$r=7$ & 53.84 & 75.73 & 46.76 & 68.86 \\
\hline$r=8$ & 36.02 & 53.42 & 29.26 & 47.20 \\
\hline$r=9$ & 23.45 & 34.79 & 16.75 & 29.37 \\
\hline$r=10$ & 11.22 & 19.99 & 8.45 & 15.34 \\
\hline$r=11$ & 3.09 & 9.13 & 0.92 & 3.84 \\
\hline
\end{tabular}

Notes:

The critical values are from Tables B.2 and B.3 in Hansen and Juselius (1995).

First, we find that the percentage of explained variation in other EMU stock markets (except for two small markets, Austria and Belgium) by each of the four large EMU markets is typically higher in period 2 than in period 1. This result implies that most EMU stock markets are more integrated with large EMU countries after the EMU was implemented. For example, the German stock market explains the error variance of the French stock market much more significantly in period $2(6.1 \%$ in period 1 vs. $12.2 \%$ in period 2 at day 20). Table 6 is constructed 


\section{Figure 1}

The Persistence Profile of the Effect of a System-wide Shock

Persistence Profile of the effect of a system-wide shock to CV'(s)

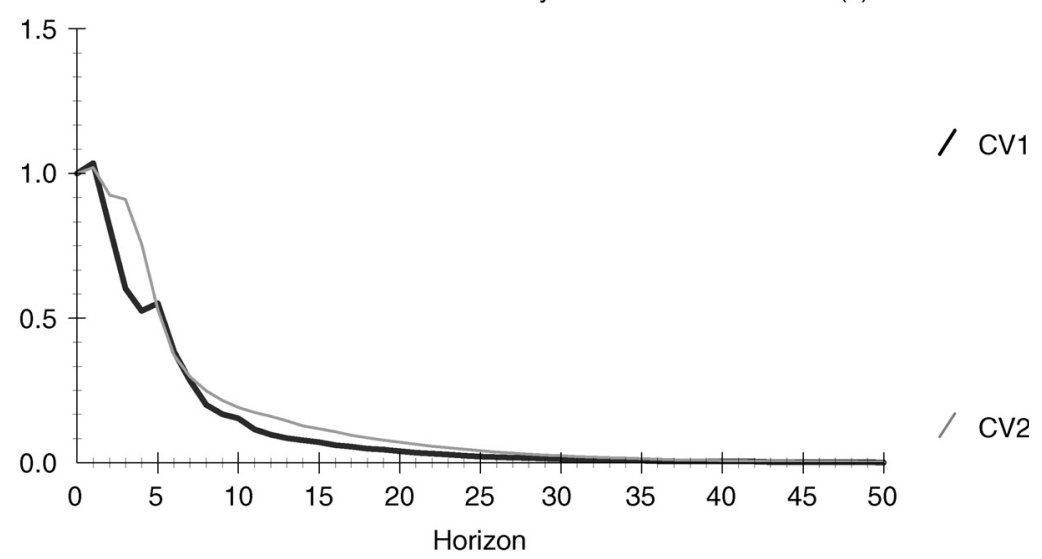

Panel A: Period 1

Persistence Profile of the effect of a system-wide shock to CV'(s)

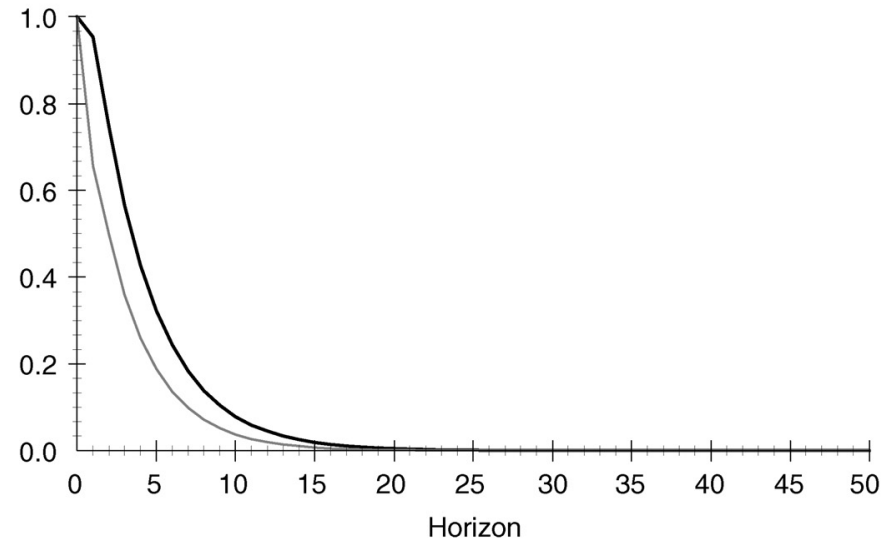

Panel B: Period 2

to show more clearly the possible different patterns of integration between two periods. In this table, each entry denotes the total percentage of forecast error variance of a particular market explained by all other stock markets (excluding its own percentage) in the categories of large and small EMU markets. 
Table 4

Generalized Forecast Error Variance Decomposition: Period 1 (day 20)

\begin{tabular}{|c|c|c|c|c|c|c|c|c|c|c|c|c|}
\hline \multirow{2}{*}{$\begin{array}{l}\text { Market } \\
\text { Explained }\end{array}$} & \multicolumn{12}{|c|}{ By Innovations in: } \\
\hline & GER & FRA & ITA & NET & AUS & BEL & FIN & IRE & POR & SPA & UK & US \\
\hline GER & 13.8 & 12.4 & 4.6 & 8.3 & 9.6 & 13.0 & 3.7 & 2.8 & 4.0 & 10.6 & 10.5 & 6.6 \\
\hline FRA & 6.1 & 22.6 & 5.4 & 6.9 & 8.8 & 12.8 & 3.5 & 3.1 & 3.1 & 11.9 & 9.9 & 5.9 \\
\hline ITA & 4.9 & 12.5 & 17.2 & 5.1 & 5.6 & 11.0 & 2.9 & 6.5 & 4.5 & 14.7 & 9.5 & 5.5 \\
\hline NET & 7.2 & 10.8 & 4.7 & 13.8 & 7.6 & 12.8 & 3.8 & 4.3 & 3.4 & 12.8 & 10.9 & 8.0 \\
\hline AUS & 7.4 & 11.3 & 4.9 & 5.3 & 25.4 & 8.4 & 5.7 & 4.4 & 3.8 & 11.0 & 6.8 & 5.6 \\
\hline BEL & 8.5 & 14.1 & 6.4 & 8.4 & 5.0 & 19.9 & 3.4 & 2.6 & 2.6 & 13.4 & 8.4 & 7.2 \\
\hline FIN & 7.8 & 10.3 & 5.2 & 7.4 & 6.7 & 9.9 & 14.7 & 4.6 & 4.0 & 11.6 & 9.0 & 8.8 \\
\hline IRE & 6.0 & 8.1 & 3.3 & 5.8 & 8.5 & 9.3 & 5.7 & 21.6 & 6.1 & 9.2 & 8.9 & 7.4 \\
\hline POR & 6.0 & 12.1 & 6.6 & 4.6 & 7.3 & 8.1 & 3.5 & 4.7 & 16.9 & 17.0 & 8.7 & 4.5 \\
\hline SPA & 5.0 & 12.3 & 6.5 & 5.5 & 7.4 & 9.3 & 2.6 & 5.4 & 5.3 & 26.2 & 8.1 & 6.3 \\
\hline UK & 6.1 & 13.1 & 4.5 & 8.3 & 6.8 & 10.5 & 3.8 & 3.5 & 4.3 & 11.1 & 20.6 & 7.5 \\
\hline US & 3.9 & 10.3 & 2.4 & 4.7 & 4.7 & 15.8 & 3.4 & 3.4 & 3.4 & 8.4 & 9.3 & 30.4 \\
\hline
\end{tabular}

Notes:

${ }^{1}$ Entries in each cell are the percentage forecast error variance of the market in the first column explained by the market in the first row.

${ }^{2}$ Forecast error variance decomposition has been standardized for each of the explained market so that the sum is $100 \%$.

Obviously, each of the large EMU markets is influenced more by other large EMU markets in period 2 than in period 1. For instance, about $34 \%$ of return variation in the German stock market is explained by the other three large EMU markets (France, Italy and the Netherlands) at day 20 in period 2, which is $8 \%$ higher than in period 1 . By contrast, the proportion of the return variation in the German market explained by the six small EMU markets in period 2 is $17 \%$ lower than in period 1. The overall impression of Table 6 suggests that large EMU markets are more integrated with other large EMU markets but less integrated with small stock markets in period 2. A similar pattern also holds for three small stock markets, Finland, Portugal and Spain. However, as we pointed out before, two small stock markets (Austria and Belgium) are more isolated in period 2. For these two markets, the percentage of return variation explained by either large or small EMU markets is substantially reduced. ${ }^{4}$

Second, the three smallest EMU markets (Austria, Belgium and Ireland) became more isolated in period 2. In period 1, 
Table 5

Generalized Forecast Error Variance Decomposition: Period 2 (day 20)

\begin{tabular}{|c|c|c|c|c|c|c|c|c|c|c|c|c|}
\hline & GER & FRA & ITA & NET & AUS & BEL & FIN & IRE & POR & SPA & UK & US \\
\hline ER & .0 & 3 & 1 & 1 & 1.7 & 5.4 & 5.2 & 04 & 5.1 & 10.5 & 8.6 & 8.7 \\
\hline FRA & 12.2 & 18.9 & 12.1 & 10.2 & 0.9 & 4.4 & 7.0 & 0.3 & 5.6 & 11.2 & 8.9 & 8.3 \\
\hline ITA & 10.7 & 12.9 & 23.0 & 11.1 & 1.0 & 3.9 & 5.4 & 0.7 & 5.0 & 13.0 & 7.4 & 6.0 \\
\hline NET & 11.9 & 12.1 & 11.1 & 15.2 & 1.4 & 7.1 & 5.0 & 0.4 & 4.1 & 10.4 & 12.1 & 9.1 \\
\hline AUS & 6.8 & 6.2 & 5.5 & 3.6 & 43.8 & 5.4 & 0.7 & 1.2 & 2.1 & 6.4 & 12.5 & 5.8 \\
\hline BEL & 4.1 & 6.1 & 3.3 & 9.2 & 3.5 & 46.5 & 0.2 & 0.9 & 3.4 & 4.9 & 8.6 & 9.3 \\
\hline FIN & 10.6 & 12.1 & 10.1 & 8.2 & 0.1 & 2.8 & 25.6 & 0.2 & 5.8 & 10.1 & 7.8 & 6.5 \\
\hline IRE & 7.5 & 7.0 & 7.8 & 7.0 & 2.1 & 7.7 & 2.5 & 35.8 & 1.0 & 7.8 & 7.5 & 6.4 \\
\hline POR & 11.6 & 9.6 & 13.6 & 8.4 & 0.1 & 3. & 7.1 & 0.2 & 21.9 & 17.1 & 3.4 & 3.3 \\
\hline $\mathrm{S}$ & 9.4 & 11.0 & 11.7 & 10.2 & 1.1 & 3 & 6.2 & 0.9 & 10.0 & 21.3 & 8.9 & 6.3 \\
\hline $\mathrm{U}$ & 8.2 & 10.2 & 9.8 & 12.6 & 2.3 & & 5. & 0.6 & 4.5 & 10.5 & 19.9 & 9.8 \\
\hline US & 9.8 & 8.8 & 6.7 & 6.5 & 0.8 & 6.4 & 1.6 & 0.0 & 2.5 & 6.1 & 8.1 & 42.8 \\
\hline
\end{tabular}

Notes:

${ }^{1}$ Entries in each cell are the percentage forecast error variance of the market in the first column explained by the market in the first row.

2 Error variance decomposition has been standardized for each of the explained market so that the sum is $100 \%$.

only $20-25 \%$ of the variation in returns is explained by own market innovations. About 35-49\% of variations are, however, explained by own innovations in period 2. Third, Spain's stock market is more influential on Portugal's stock market in both periods ${ }^{5}$. From Tables 4 and 5, Spain's stock market explains about $17-21 \%$ of the return variations in Portugal's market on day 20, which is the largest impact among all other EMU countries.

Generalized impulse response functions associated with four large EMU stock markets are also conducted but not shown here to conserve space. Different from the persistence profiles (Figure 1), which measure the effect of a system-wide shock on the cointegrating (or long-run) relations among the European markets, the generalized impulse response functions examine the dynamic effects of a market-specific shock on each of the markets in the system. In general, the findings from these generalized impulse response functions (which are normalized and in response to a one-standard-deviation shock) provide further support for the variance decomposition results. In 
Table 6

Generalized Forecast Error Variance Decompositions: Large vs. Small Stock Markets

\begin{tabular}{|c|c|c|c|c|c|}
\hline \multirow[b]{3}{*}{ Market Explained } & \multirow[b]{3}{*}{ Days } & \multicolumn{4}{|c|}{ By Innovations in: } \\
\hline & & \multicolumn{2}{|c|}{ Large EMU Countries } & \multicolumn{2}{|c|}{ Small EMU Countries } \\
\hline & & Period 1 & Period 2 & Period 1 & Period 2 \\
\hline \multirow[t]{3}{*}{ GER } & 5 & 27.7 & 34.1 & 40.1 & 28.3 \\
\hline & 10 & 26.9 & 34.3 & 41.4 & 28.3 \\
\hline & 20 & 25.3 & 34.4 & 43.7 & 26.6 \\
\hline \multirow[t]{3}{*}{ FRA } & 5 & 24.2 & 34.0 & 37.9 & 29.5 \\
\hline & 10 & 21.7 & 34.3 & 39.9 & 29.4 \\
\hline & 20 & 18.4 & 34.5 & 43.2 & 28.5 \\
\hline \multirow[t]{3}{*}{ ITA } & 5 & 25.8 & 34.3 & 38.8 & 29.0 \\
\hline & 10 & 24.9 & 34.4 & 41.2 & 29.0 \\
\hline & 20 & 22.5 & 34.7 & 45.2 & 28.0 \\
\hline \multirow[t]{3}{*}{ NET } & 5 & 24.9 & 33.6 & 39.9 & 29.8 \\
\hline & 10 & 24.2 & 34.4 & 41.5 & 29.1 \\
\hline & 20 & 22.7 & 35.1 & 44.7 & 27.0 \\
\hline \multirow[t]{3}{*}{ AUS } & 5 & 30.6 & 21.9 & 32.4 & 17.0 \\
\hline & 10 & 30.3 & 22.0 & 32.5 & 16.4 \\
\hline & 20 & 28.9 & 21.1 & 33.3 & 15.8 \\
\hline \multirow[t]{3}{*}{ BEL } & 5 & 36.9 & 24.8 & 25.7 & 12.4 \\
\hline & 10 & 37.9 & 23.7 & 25.8 & 12.5 \\
\hline & 20 & 37.4 & 22.7 & 27.0 & 12.9 \\
\hline \multirow[t]{3}{*}{ FIN } & 5 & 33.7 & 39.5 & 31.6 & 19.3 \\
\hline & 10 & 32.8 & 40.2 & 33.9 & 19.1 \\
\hline & 20 & 30.7 & 41.0 & 36.8 & 19.0 \\
\hline \multirow[t]{3}{*}{ IRE } & 5 & 27.0 & 26.2 & 34.7 & 18.6 \\
\hline & 10 & 25.6 & 27.7 & 37.2 & 19.8 \\
\hline & 20 & 23.2 & 29.3 & 38.8 & 21.1 \\
\hline \multirow[t]{3}{*}{ POR } & 5 & 31.5 & 38.9 & 33.2 & 23.8 \\
\hline & 10 & 30.8 & 41.0 & 35.8 & 25.7 \\
\hline & 20 & 29.3 & 43.2 & 40.6 & 28.2 \\
\hline \multirow[t]{3}{*}{ SPA } & 5 & 34.6 & 43.1 & 27.6 & 20.8 \\
\hline & 10 & 32.7 & 42.7 & 28.1 & 21.0 \\
\hline & 20 & 29.3 & 42.3 & 30.0 & 21.2 \\
\hline \multirow[t]{3}{*}{ UK } & 5 & 34.9 & 39.5 & 36.0 & 28.3 \\
\hline & 10 & 36.0 & 40.1 & 36.2 & 28.8 \\
\hline & 20 & 32.0 & 40.8 & 40.0 & 29.5 \\
\hline \multirow[t]{3}{*}{ US } & 5 & 24.7 & 31.3 & 31.9 & 17.4 \\
\hline & 10 & 23.4 & 31.5 & 35.2 & 17.4 \\
\hline & 20 & 21.3 & 31.8 & 39.1 & 17.4 \\
\hline
\end{tabular}

Note:

Each entry is computed as the sum of percentages included in each category, but its own decomposition is excluded. 
particular, three large EMU markets (France, Italy and the Netherlands) are more responsive to innovations in Germany in period 2 on day 20. For example, the size of response of the French stock market is 0.36 on day 20 in period 1, while it is 0.75 in period 2. For small stock markets, it is again found that Austria, Belgium and Ireland, which have been identified to be more isolated in period 2, respond significantly less to innovations in Germany in period 2 than in period 1.

Similar linkage patterns are observed with respect to the French stock market. Two large stock markets (Germany and the Netherlands) ${ }^{6}$ and some small stock markets (Finland and Spain) are more responsive to shocks from the French stock market in period 2 and two small markets (Austria and Belgium) respond substantially less in period 2. It is also interesting to note that many EMU stock markets are most responsive to a shock in the French stock market after the establishment of the EMU. In particular, in period 2, the size of response of the German stock market to innovations in the French stock market is 0.94 on day 20, while the size of response of France to innovations in the German stock market is only 0.75 on day 20. The Netherlands stock market is also more responsive to innovations in France than in Germany in period 2. This pattern is also true for most small stock markets. For example, while the size of response in Spain is 0.65 with respect to a shock in Germany in period 2, the size of response is 0.77 with respect to innovations in France.

The same pattern also holds for Italy and the Netherlands: other large EMU markets respond to a shock from these two large EMU markets much more significantly in period 2 than in period 1 . In sum, the impulse response analysis confirms that each of the large EMU stock markets became more integrated with other large EMU markets in the short run after the EMU launched. The impulse response analysis results for small markets (not reported here but available on request from the authors) are also consistent with the forecast error variance decomposition results.

We also examine whether and how the EMU may affect the dynamic linkage pattern between EMU markets and the UK and the US, which are not members of the EMU. It is obvious from Tables 4 and 5 that four large EMU markets have not become more integrated with the UK stock market in period 2. 
On the contrary, the impact of the UK stock market on three large EMU stock markets (Germany, France and Italy) is reduced in period 2. This is also further confirmed by the generalized impulse response analysis. Most large EMU stock markets become less responsive to the UK stock market in period 2, which is similar to the results based on forecast error variance decomposition. In particular, in period 2 , the impact of the UK stock market on Germany and Italy is much smaller than the impact of France on the two stock markets. For example, the size of the German response to a shock in the UK is 1.07 and the size of the German response to a shock in France is 0.80 on day 1 in period 1 . By contrast, the size of the German response is 0.93 to a shock in the UK and 0.95 to a shock in France on day 1 in period 2. Apparently, relative to the UK stock market, the French stock market became more influential on other EMU stock markets. Thus, the EMU caused stock markets in member countries to be less integrated with stock markets in non-member countries (i.e., the UK). The finding provides indirect evidence for the impact of the EMU on European stock markets.

As for the impact of the EMU on the dynamic linkage between European stock markets with the US, no clear pattern can be discovered yet. Two large EMU markets, Germany and France, respond more to a shock in the US in period 2 at day 20, while the other two large EMU markets, Italy and the Netherlands, respond less in period 2. Thus, it may not be definitively asserted that large EMU stock markets become more integrated with the US stock market after the EMU. The same thing can be said about the relationship between small EMU markets and the US. Also, as indicated in Tables 4 and 5, the US stock market is one of the most exogenous markets in terms of movements explained mainly by own variation (period 1 , around $40 \%$ and in period 2, about $44 \%$ ). This is consistent with previous research such as Dekker, Sen and Young (2001) and Masih and Masih (1999).

Finally, the impact of the EMU on the contemporaneous structure of market integration is examined by testing equality of corresponding correlation coefficients of market innovations (i.e., residuals from the estimated ECM models) in the two periods. A significant increase in correlation coefficients implies 
that the two stock markets have become more integrated contemporaneously in the second period. Test results are reported in Table 7.

In general, the findings in Table 7 are consistent with the short run dynamic structure of market integration reported previously. Correlation coefficients between large EMU markets are significantly increased in period 2 . Hence, we can conclude that large EMU markets also became more integrated among themselves contemporaneously. For example, the correlation coefficient between Germany and France increases significantly from 0.63 in period 1 to 0.77 in period 2. The increase in correlation coefficient between Italy and France is also statistically significant ( 0.66 in period 1 vs. 0.76 in period 2). Also consistent with the short-run dynamic linkage pattern, correlation coefficients between the UK and large EMU markets do not increase significantly. Thus, the UK stock market did not become more integrated contemporaneously with other large EMU stock markets. Another finding is that Spain is more correlated with the four large EMU markets in period 2. In addition, for three small countries (Austria, Belgium and Ireland) the contemporaneous correlation coefficients with most other EMU countries are significantly decreased. Between Austria and Germany, the correlation coefficient is reduced from 0.63 to 0.37 . This result is in line with previously reported findings based on the short run dynamic structure that these smallest stock markets became more isolated after the EMU.

\section{CONCLUSIONS}

This study examines the long-run, short-run and contemporaneous structures of integration among eleven European stock markets and US, with particular attention paid to the issue of how the establishment of the Economic and Monetary Union (EMU) affected stock market integration among the EMU markets and major non-EMU markets (the UK and the US). Our findings are consistent with most previous studies (Taylor and Tonks, 1989; Corhay, Rad and Urbain, 1993; Dickson, 2000; and Leachman and Francis, 1995) in that two cointegrating 


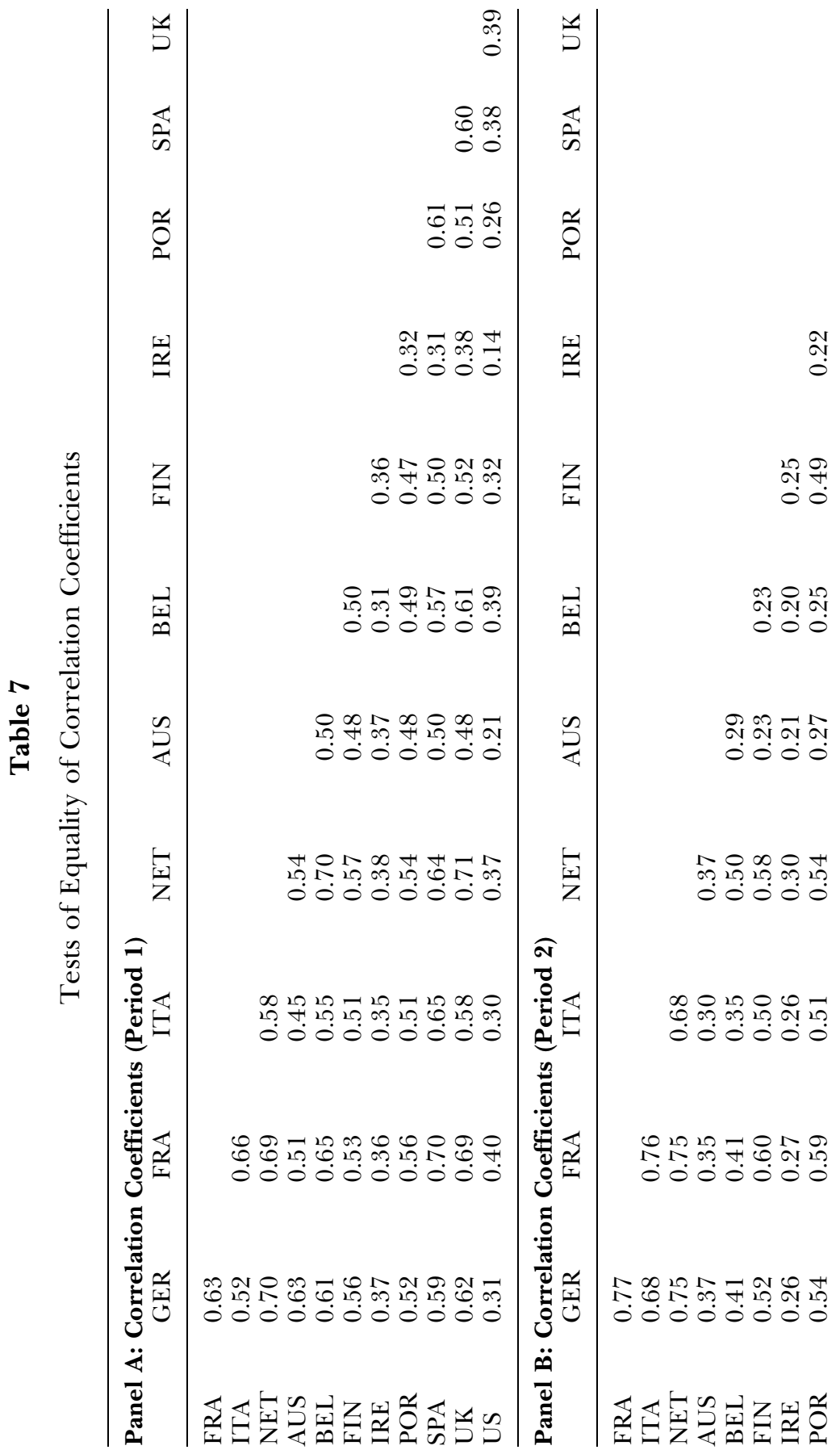




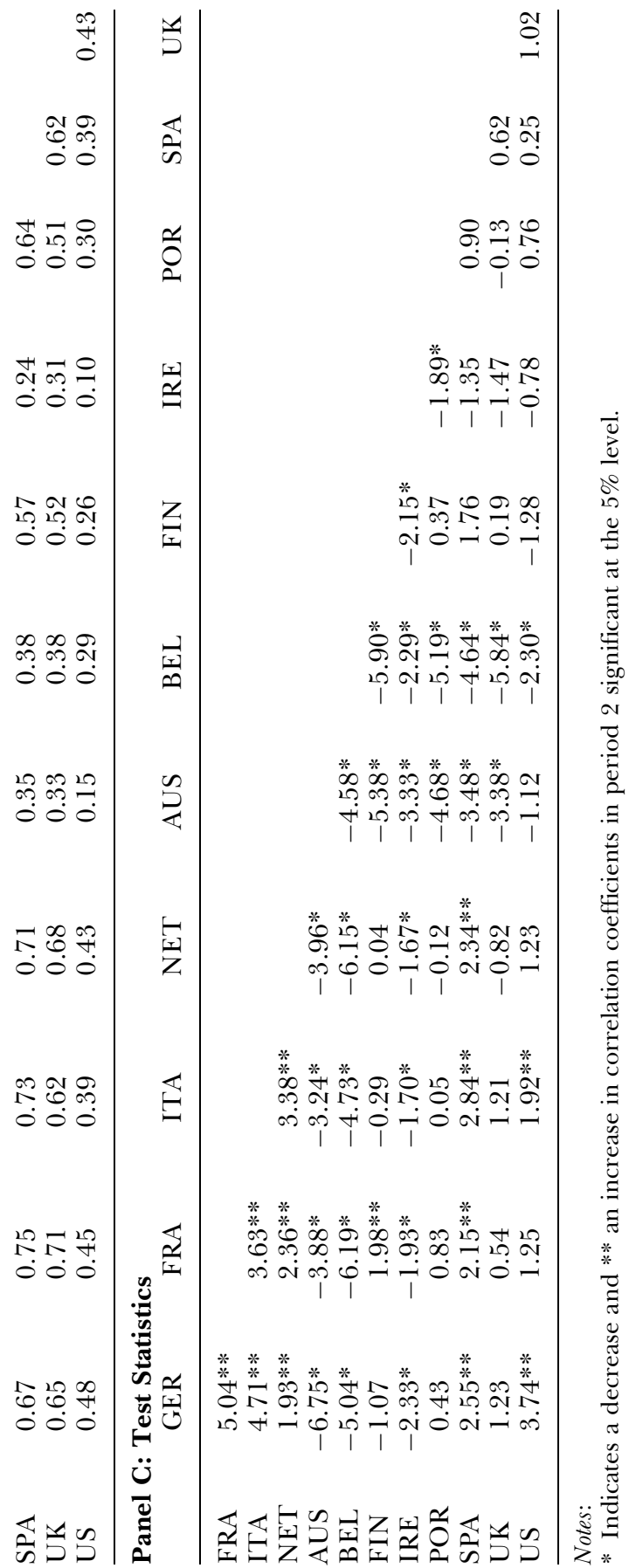

C Blackwell Publishing Ltd 2003 
vectors are found in both the periods before and after the EMU. Furthermore, the long-run linkages among these markets generally strengthened after the EMU, because the long-run relationships are restored more quickly after system-wide shocks.

To further investigate the impact of the EMU on the shortrun dynamic structure of international market integration, generalized impulse response analysis and generalized forecast error variance decomposition are conducted based on the ECM with the imposition of long-run relationships. The results clearly indicate that large EMU markets (Germany, France, Italy and the Netherlands) are more integrated with each other after the EMU. Several small EMU markets are also more integrated with the large EMU markets, while the three smallest EMU markets (Austria, Belgium and Ireland) became more isolated from other EMU markets after the EMU launched. Shedding more light on the controversy between Pynnonen and Knif (1998) and Knif and Pynnonen (1999), our finding suggests that after controlling for macroeconomic environments, only too small a market size may give rise to the concern of market liquidity and become an obstacle for active participation of international investors. Hence, for very small stock markets such as Austria, Belgium and Ireland, market interrelationships between them and other stock markets may not be an adequate reflection of their macroeconomic linkages with other countries. Interestingly, it is also found that the EMU markets seem to be less integrated with the UK after establishment of the EMU, which provides indirect positive evidence for significant impact of the EMU on European stock market integration. Also, no clear pattern has emerged yet regarding their integration with the US. The contemporaneous structure of integration is also examined, which yields similar inference as presented above.

In conclusion, the EMU has significantly strengthened stock market integration among its member countries, but lessened linkages with a non-member country (UK) in the same region. This finding is consistent with the argument that macroeconomic factors may partly drive stock market movements (Leachman and Francis, 1995; and Dickson, 2000) and extends previous studies (e.g., Chan, Gup and Pan, 1997) which did not find a higher degree of market integration among European 
stock markets associated with apparent stronger economic ties under the process of regional economic integration (i.e., the European Economic Community). It should be mentioned that the increased integration among European stock markets might also be attributable to faster information transmission and processing due to technological advances, recent consolidation and merger of stock exchanges in Europe, etc. It is difficult to disentangle the impact of EMU from other channels that might also affect European stock market integration. The finding of this paper should be subject to further examination. Future research may be extended to explore the possible impact of the EMU on integration between other European stock markets with the EMU markets and the impact of other regional economic integration schemes on stock market integration.

\section{NOTES}

1 The Luxembourg stock market is the only EMU market which is not considered in this study due to lack of the stock index price data. The data unavailability, however, may be a reflection of the fact that the market is almost the smallest among eleven EMU markets in terms of market capitalization (see Table 1).

2 As pointed out by the referee, the impact of the EMU on European stock market integration may be to an extent anticipated during the period before the EMU. However, the extent to which the impact of the EMU is anticipated before it was implemented is a question open to empirical testing. The finding of a significantly increased degree of market integration in this study may serve a conservative estimate of the impact of the EMU on European stock market integration, which also suggests that such an impact is to a large extent unanticipated. The comparison between the period of 1999-2001 and that of 1989-1991 confirms that European stock markets have been more integrated after the establishment of the EMU.

3 This follows the convention as given in Eun and Shim (1989). The analysis is also conducted using the data converted to US dollars. The findings are basically the same as those presented in the paper.

4 The Ireland stock market is less explained by four large EMU stock markets in period 2 at day 1 and 5, but more explained at day 10 and 20. Thus, the pattern of its integration with large EMU markets is not uniform.

5 One might argue that the influence of Spain on the Portugal stock market is due to geographical proximity. However, as pointed out by the referee, if such a factor is dominant, we should expect a strong linkage between the Netherlands and Belgium. Thus, the reason why the Spanish market has significant influence on the Portugese market remains an open question for future research.

6 The Italian stock market seems a bit more responsive in period 1 to innovations in France, but the difference between the two periods is very slight. 


\section{REFERENCES}

Bessler, D.A., and J. Yang (2003), 'The Structure of Interdependence in International Stock Markets,' Journal of International Money and Finance, Vol. 22, pp. 261-87.

Brocato, J. (1994), 'Evidence on Adjustments in Major National Stock Market Linkages Over the 1980s,' Journal of Business Finance E Accounting, Vol. 21, No. 5 (July), pp. 643-67.

Chan, K.C., B.E. Gup and M. Pan (1997), 'International Stock Market Efficiency and Integration: A Study of Eighteen Nations,' Journal of Business Finance Eं Accounting, Vol. 24, No. 6 (July), pp. 803-13.

Corhay, A., A.T. Rad and J.P. Urbain (1993), 'Common Stochastic Trends in European Stock Markets,' Economics Letters, Vol. 42, pp. 385-90.

Dekker, A., K. Sen and M. Young (2001), 'Equity Market in the Asia Pacific Region: A Comparison of the Orthogonalized and Generalized VAR Approaches,' Global Finance Journal, Vol. 12, pp. 1-33.

Dickey, D.A. and W.A. Fuller (1981), 'The Likelihood Ratio Statistics for Autoregressive Time Series with a Unit Root, Econometrica, Vol. 49, pp. 1057-72.

Dickinson, D.G. (2000), 'Stock Market Integration and Macroeconomic Fundamentals: An Empirical Analysis, 1980-95,' Applied Financial Economics, Vol. 10, pp. 261-76.

Eun, C. and S. Shim (1989), 'International Transmission of Stock Market Movements,' Journal of Financial and Quantitative Analysis, Vol. 24, pp. 241-56.

Francis, B. and L. Leachman (1998), 'Superexogeneity and the Dynamic Linkages Among International Equity Markets,' Journal of International Money and Finance, Vol. 17, pp. 475-92.

Gerrits, R.J and A. Yuce (1999), 'Short- and Long-term Links Among European and US Stock Markets, Applied Financial Economics, Vol. 9, pp. 1-9.

Hansen, H. and K. Juselius (1995), CATS in RATS: Cointegration Analysis of Time Series (Evanston, Illinois: ESTIMA).

Janakiramanan, S. and A.S. Lamba (1998), 'An Empirical Examination of Linkages Between Pacific-Basin Stock Markets,' Journal of International Financial Markets, Institutions and Money, Vol. 8, pp. 155-73.

Johansen, S. (1991), 'Estimation and Hypothesis Testing of Cointegration Vectors in Gaussian Vector Autoregressive Models,' Econometrica, Vol. 59, pp. 1551-80.

- and K. Juselius (1990), 'Maximum Likelihood Estimation and Inference on Cointegration - With Application to the Demand for Money,' Oxford Bulletin of Economics and Statistics, Vol. 52, pp. 169-210.

Kendall, M.G. and A. Stuart (1967), 'The Advanced Theory of Statistics,' Charles Griffin.

Knif, J. and S. Pynnonen (1999), 'Local and Global Price Memory of International Stock Markets,' Journal of International Financial Markets, Institutions and Money, Vol. 9, pp. 129-47.

Koch, P. and T. Koch (1991), 'Evolution in Dynamic Linkages Across Daily National Stock Indexes,' Journal of International Money and Finance, Vol. 10, pp. 231-51.

Koop, G., M.H. Pesaran and S.M. Potter (1996), 'Impulse Response Analysis in Nonlinear Multivariate Models,' Journal of Econometrics, Vol. 74, pp. 119-47. 
Leachman, L.L and B. Francis (1995), 'Long-Run Relations Among the G-5 and G-7 Equity Markets: Evidence on the Plaza and Louvre Accords,' Journal of Macroeconomics, Vol. 17, pp. 551-77.

Lutkepohl, H. and H. Reimers (1992), 'Impulse Response Analysis of Cointegrated Systems,' Journal of Economic Dynamics and Control, Vol. 16, pp. 53-78.

Mahmoud, W. and L. Malek (1993), 'Some Joint Tests of the Efficiency of European Equity Markets,' Journal of Multinational Financial Management, Vol. 2, pp. 127-66.

Masih, A. and R. Masih (1999), 'Are Asian Stock Market Fluctuations Due Mainly to Intra-Regional Contagion Effects? Evidence Based on Asian Emerging Stock Markets,' Pacific-Basin Finance Journal, Vol. 7, pp. 251-82.

Pesaran, M.H. and Y. Shin (1996), 'Cointegration and Speed of Convergence to Equilibrium,' Journal of Econometrics, Vol. 71, pp. 117-43. (1998), 'Generalized Impulse Response Analysis in Linear Multivariate Models,' Economics Letters, Vol. 58, pp. 17-29.

Phillips, P. and P. Perron (1988), 'Testing for a Unit Root in Time Series Regression,' Biometrica, Vol. 75, pp. 335-46.

Pynnonen, S. and Knif, J. (1998), 'Common Long-term and Short-term Price Memory in Two Scandinavian Stock Markets,' Applied Financial Economics, Vol. 8, pp. 257-65.

Ripley, D.M. (1973), 'Systematic Elements In the Linkage of National Stock Market Indices,' Review of Economics and Statistics, Vol. 55, pp. 356-61.

Sims, C. (1980), 'Macroeconomics and Reality,' Econometrica, Vol. 48, pp. 1-48.

Taylor, M.P. and I. Tonks (1989), 'The Internationalization of Stock Markets and the Abolition of U.K Exchange Control,' Review of Economics and Statistics, Vol. 71, pp. 332-36.

Yang, J., J.W. Kolari and I. Min (2003), 'Stock Market Integration and Financial Crises: The Case of Asia,' Applied Financial Economics, Vol. 13, pp. 477-86. 